\title{
"Impressing Heaven": Creative Non-fiction as Reflective Practice in Foreign Language Teaching and Cross Cultural Study
}

\author{
Barbara Waldern \\ Division of English, Busan University of Foreign Studies, South Korea
}

Copyright (C) 2015 by authors, all rights reserved. Authors agree that this article remains permanently open access under the terms of the Creative Commons Attribution License 4.0 International License

\begin{abstract}
Impressing Heaven" is the title of my collection of short stories about career decisions and experience interacting in English on the part of actual young adult learners of English as a foreign language in South Korea. (See Impressing Heaven by Barbara Waldern, July 2012 Smashwords ISBN: 9781476467023). While I was first settling in Korea, I got acquainted with a few students and other young adults who liked to talk with and assist English speaking foreigners. They made such a strong impression that I remembered them and thought about our conversations over the years. I ended up writing about them, imagining their real life situations as they had confided in me, or envisioned how their lives would proceed thereafter. I interwove their narrations with my narration of my experience with them to put myself in the shoes of others. This collection thereby serves as a journalistic reflection of some of my first encounters with such students of English as well as a preservation of memories. Given the artistic approach to this work, it is not standard social science although it is a useful exploratory activity, and can be used as one tool of reflective practice in educating, understanding, or relating to a particular cultural group as an outsider. I conclude that this form of creatively written journal keeping serves reflective practice and could contribute to sound methodological and anthropological study as an additional tool of ethnographic research and pedagogical research.
\end{abstract}

Keywords Creative Non-fiction, Qualitative Methods, Journal Writing, Reflective Practice, Reflective Teaching, Cross-cultural Study, EFL Methods

\section{Introduction}

In this article, I extend my thoughts as presented in conferences and conference papers on a discovery I have made about journal writing. The subject of this paper is a discussion and further reflection of my experience writing a teacher's journal using creative writing techniques. This time around, I will reflect further on the value of creative non-fiction writing as reflective teaching and research practice. I will use a storytelling style befitting the subject matter here to further demonstrate the effectiveness of creative writing techniques in non-fictional writing.

Impressing Heaven (Waldern, 2012, Smashwords Inc. ISBN: 9781476467023) is a collection of short stories based on real conversations with real young adult learners of English in South Korea from 2007 to 2010. What began as a personal project of writing fiction turned into a kind of record of my experience with these people. My growing awareness about the Korean culture kept resurfacing in the process, so much so that I ended up writing about them in a creative narrative style.

I moved to South Korea on an English teaching employment contract in 2007. After several of these individuals relayed their life situations and dilemmas to me, I imagined the unfolding drama of struggling with identity, negotiating global English, and making career decisions, putting myself in their shoes to reflect deeply on their situation as young adult learners of English in South Korea. "Impressing Heaven" is therefore an example of the production and use of a journal in reflective (foreign language) teaching.

My journal writing has continued with growing awareness and refined practice, though I have also been writing creative fiction since 2008. For instance, journal writing is often a required activity in my classes. Outside the classroom, journal writing has continued to help enhance my sensitivities, decision making, choices, goal setting, relationships management, and perspective on my environment and life in positive ways.

The process of journal writing can contribute to sharper assessments, purposes and objectives, as well as methods of working, living and relating interpersonally.

Teachers who use journal writing as a method of self-reflection of teaching generally describe and reflect on the lesson planning, the lesson planning process, the application of the methods in the classroom and the observed 
implementation, and the student responses to the methods. They usually discuss how successful the methods have been and how the methods might be developed or substituted. They might also discuss the teacher-student relationship.

All journal writing is simultaneously an investigative method and a learning process. Teachers often employ journal writing as a student activity in their classes to facilitate and extend learning. Say Dyment \& O'Connell, "One of the most recognized uses of journals is to help facilitate reflection, a critical component of the experiential education cycle. Through journals, students can record a concrete experience, reflect on and record their observations about the experience, integrate the observation into abstract concepts or theories, and use the theories to make decisions or solve problems. " [1].

Engagement is another goal of journal composition. Fritson, Forrest and Bohl talk about the many benefits of student journal writing. In addition to understanding materials better, journal writing lends some autonomy and builds skills. As well, they say [2], "Journal writing also influences student engagement in a variety of ways." (It is beneficial in building trust mutual awareness, attention and responsibility.) By aiding reflection, it makes the author more engaged with himself and the environment. It is an outcome of recording observations, noting responses, and thinking about them. Journal writing, then, can bring about social and psychological consequences.

What about the teacher is writing his or her own journal so as to facilitate learning about teaching, and learning about students? Humble and Sharp [3], experts in qualitative research methods themselves, wrote about their project of keeping and sharing a journal about their experience in teaching graduate students. Using Flavell's term "metacognition," they claim that journal writing enhances metacognitive awareness, and they identified three benefits of teacher journal writing through their project: clarity, confidence and connection. They further quote Kaplan, Rupley, Sparks and Holcomb (2007) who claim that journaling for educators enhances the educator's learning through examination, clarification and critique of pedagogical ideas and practices over both the short and long term. They all say that pedagogical reflection can take any of four forms: descriptive writing, (b) descriptive reflection, (c) dialogic reflection, and (d) critical reflection.

Journal writing thus can thus serve to enhance critical thinking and problem-solving. According to Fritson, Forrest and Bohl, speaking on the benefit of metacognition, "[Reflective] such journals promote reflection on and articulation of students' thinking and problem solving strategies (Fogarty \& McTighe, 1993). Students become better at recognizing and addressing their deficits while, at the same time, improving problem-solving skills (Clarke, Waywood, \& Stephens, 1993). Finally, reflective journals can assist students in effectively acquiring and transferring cognitive and metacognitive skills across disciplines (Perkins, Simmons, \& Tishman, 1990).” [4]

Journal writing is also a form of storytelling. It can adopt a journalistic style, by taking the form of a log, for example, or some kind of rendition of the facts, but the fact that the author has a perspective and chooses and colours the facts cannot be escaped. It is still a process of telling the story of what happened. Going further, one can editorialize the record of the facts to add commentary here and there, recording some reflection and thereby expressing a response to what happened (although just the response of remembering events is a response). As a personal diary, the writer usually allows her or himself to explore the emotional side of experience. In that kind of diary, the characters and events are more selective, in that the writer may have been reflecting on one situation, or person or happening more than others, so that there is a more refined focus on a subject matter that the author wishes to reflect upon and express some response to. That kind of private journal writing fosters a more creative writing style, though it may not actually engage in the telling of a story. An educator or researcher, or anyone of any occupation, can create personal journal writing just to be more aware, or to increase understanding, or solve problems such as how to interact with someone or prioritize some business or make a decision and so on. This last kind of journal writing can be done systematically, and shared within a select group, such as for management purposes or therapy or exploring group processes. As well, such people can have clients write journal on an open basis or on specific topics with the agreement that a professional is going to read and review them, and perhaps offer responses, or that some clients may read to or show excerpts to each other for discussion, and so on.

Both as a foreign language instructor and as a former student of anthropology, I can now better appreciate the implications and potential applications of creative non-fiction in social research, particularly ethnographic study. Forms of narration have emerged as a legitimate and often required scholastic style of scientific writing in the social sciences so as to more deeply understand and empathize with the communities that are researched. Narration can allow the person studied to speak for themselves, resist objectification of people and culture, and circumvent staid conventions and ethnocentric biases of practice. As such alternate practices have gone forward, creative non-fiction in research writing has come to be more valued.

For example, The Cultural Anthropology Journal invites creative non-fiction contributions. Two of its editors, Byler and Iverson, point out that the genres of fiction and non-fiction have expanded and sometimes overlap. Fiction borrows from non-fiction, and vice-versa. The editors state that all accepted submissions The Cultural Anthropology Journal are "concerned with clarifying, exploding, magnifying, or subverting different kinds of truths." [5] They provide a brief overview of the history of the relationship between literature and anthropology. To quote Byler and Iverson once again:

"This history is much longer than is usually acknowledged, in large part because ethnography is most often a written 
description of lifeways.[1] Though works of "ethnographic fiction" were frequently written by prominent anthropologists in the 1920s and 30s, the discipline (as a budding "science") eventually began to discourage "novelistic" writing ... Since that early period, anthropology has experienced several "literary turns," punctuated by Clifford Geertz's 1973[4] exhortation to produce "thick description." Geertz's work was followed by literary modes influenced by postmodern critiques, including reflexivity (e.g. Rosaldo 1991[5]), experimental forms, and an acknowledgement of positioning and authorship [6] that often resulted in scholarship that overlapped with memoir [6]."

Narayan stands by Geertz's recommendations. She writes [6]: “...Geertz was encouraging ethnographers to acknowledge a wider literary movement. This movement-which uses some of the storytelling techniques of fiction to write about actual events - first coalesced in the 1960s and early 1970s with the New Journalism advocated by Tom Wolfe and others, then gained momentum in subsequent years to inform assorted kinds of writing. The movement has come to include such genres as personal essays, memoirs, nature writing, travel writing, literary journalism, and cultural criticism, and is now institutionalized through courses, grants, writing degree tracks, and journals." Narayan identifies and elaborates on specific tools of creative non-fiction often used in ethnographic writing. They are situation, story, character, scenes, summaries, and expository lumps.

\section{The Project}

My experiment was a reflection of the context, identity and purpose of the learner in acquiring English proficiency through formal schooling and other means. In addition, it is an examination of the relationship between a teacher of English as a foreign language and other learners of English as a foreign language. My project was an exercise in thinking about the English language learners I had been meeting in the first years of my life in South Korea, not all of whom were my students.

It must be pointed out that this project did not begin as a reflective journal writing project, though it was a result of reflection of my role and experience as a teacher, in and outside the class. Rather, the journal writing began by accident. It really arose out of my growing interest in writing short fictional stories with fictional characters inspired by real people. As I began to write, the memory of a few of the young adult learners of English as a foreign language in my personal encounters and conversations with them kept occupying my mind and I found myself writing about them and their actual words and circumstances instead of inventing stories. I ended up creating a way of recording and relishing memories.

Then I began to see the implications for teaching, which I have wanted to discuss with teachers and other professionals working in cross-cultural settings. The work was creative in that I extended or filled in gaps of the stories of my "subjects" as they had told them to me, imagining how they must have experienced certain life episodes I knew had occurred, or how resolutions to their questions and decision-making processes may have played out. Thus, I was equipped with facts, and I dramatized anecdotes of my experience with them or the anecdotes of their lives that they had described to me on paper. It was later that I realized I had, in fact, composed a sort of journal, though not a type of journal I had ever heard about. I found it was a good way to review things, and that reviewing had benefits for teaching and for strangers in a strange land.

All the same, I used caution in that I changed names and some of the circumstances so as not to expose the real people involved. As it had begun as a personal and private exercise, I had not sought the permission of the subjects. Using creative fiction, though, allows me to bring to light the stories of the people I met so that others can learn about them, even other students, and reflect on the cultural environment, while concealing the identity of the characters in the stories who were real-life figures.

The presentations of these characters and the stories from their real lives are positive. Taking the position as an optimist, I focused on the good things though, of course, problems and dilemmas are the springboards for each story. Each character meets with success in life after addressing questions or struggling with a conflict in determining and carrying out their study and career paths related to their interest in and use of English.

I first decided to prepare and print out the pages of these stories in order to use them as material in a senior level university discussion class, adding discussion questions and a glossary of more difficult vocabulary for this class. That is the version of e-book that exists to date.

Overall, I became more aware of the cultural context of the young adult Korean speakers of English that I had encountered. I understood their motivation to learn and use English better, and the family and society's interest in English language society.

The title of the work sums up my findings of this project. "Impressing Heaven" refers to a saying in the Korean language, which is, "Heaven will be impressed if you are very sincere and industrious. (지성이면 감천이다)." It is good clue to the work ethic of Korea. For one thing, hard work is a sign of authenticity. The idea is that hard work is more than just a means to achieve prosperity; it is also a moral question and an indication of fine character. A hard working person will be recognized and praised in the afterlife. There will be more rewards bestowed by Heaven if one is sincere and industrious. Korean children are taught to dream big and persevere in working industriously. It is an aspect of the nation building project of the society, as a matter of fact. The saying thus reveals a simultaneously romantic view that is nonetheless materialistic. Being industrious means producing, supporting the family and giving to others, for which Heaven will pay one back 
eventually.

I thereby gained cultural insight into my context of teaching English to Koreans in the education system in South Korean society. The stories exposed the existence of these ideals, and the conflicts and contradictions in contemporary lives of English learners in South Korean society. For example, one story highlighted the competitive environment of the learner and working person. I developed that story by reflecting on the relationships among competing students in a classroom and how their conversations and responses to each other might have taken shape. Another story brought to light the relationships between students and families, including the conflicting concerns and demands of family on their growing children. This story grew as I imagined the conversations within the family, and how the young person must have felt. A third story exposed the tough and exasperating realities of working life for Koreans using English at work. Drawing from my own experiences when I was starting out in the working world, I could relate and imagine how the young person thought and felt from the point of preparing for the job, to handling stress and overwork and difficult coworkers, to entertaining a decision to make a change; that story developed so.

\section{Discussion}

However it is done, the process of journal writing helps the teacher to look at their own work and social position and those of their colleagues and students from various angles, and in the micro and macro contexts. It is a process of discovery that shines light on previously hidden factors and phenomena and guides a teacher or student towards a decision. The process helps consciousness to awaken, concepts to grow, relationships to mature, methods to crystallize, and patterns to emerge. Above all, it makes more changes more possible.

Writing about these learners and reflecting on them has brought about many benefits. I gained a lot of insight through this kind of reflection. It has helped me to understand the culture in which I work, the context in which English is being taught and learned, the range of specific goals that these learners hold dear, and some of the obstacles to their career development and implementation of the learned language at work. Specifically, this project highlighted three areas of the concerns of students: struggling with identity, negotiating global English, and making career decisions. Furthermore, I have been able to use the stories as a teaching material, and shared it with other teachers for their consideration.

I have come to understand journal writing as a powerful investigative, skills building and consciousness raising. Furthermore, I have come to realize that it is a form of story writing and expanded by deliberately employing creative writing techniques. I have also learned that there are many kinds of teacher and student journals.
I now appreciate the use of creative writing tools in analysis and report writing. Narrative technique employed in the social sciences was originally intended to admit and reveal the perspective and voice of the researcher as one of the many players on the research and education stages. It also allows for experiential discovery, which is emotional and sensory exploration that can uncover substance within the cracks in the walls between the staid and ideal "facts". That sort of substance is part of the objective reality.

Using the creative writing technique in reflective teacher journal writing has enhanced my reflective process and enhanced my understanding, lending me more insight than I would have had, had I simply written a standard journal. It has helped me to see myself in a situation among other people and better understand how I may affect them and they me, and how others may see and understand me. At the same time, this form of teacher journal writing is not all about the teacher, although the teacher often exists as a character in the stories. More precisely, it helps to increase an educator's and researcher's sensitivities. Creative non-fiction allows the teacher see themselves as an evolving character of the story, to reflect more deeply about who he or she is teaching, why the students are there and what they want and what kind of challenges they face, and how the teaching of a foreign language can affect students' lives. At the same time, creative non-fiction in pedagogical journal writing can help the teacher to reflect more on how she perceives her students, how she is teaching them, what she thinks students ought to gain from her teaching, the nature of the educational system and work life in the society where her students and she lives and works, and what students want from the teacher-student relationship. This particular technique of creative non-fiction journalism could also be a form of supplementary data gathering and analysis in social research, including ethnography. I know I am definitely more informed and more aware after having written these stories, reviewed them, used them in the classroom and shared them in discussions of pedagogy and qualitative methods of research.

Reflective journal writing, especially as bolstered by the use of creative writing techniques, can highlight the need for changes to research and teaching practices. Moreover, it can motivate the educator or researcher to make adjustments. As well, it can give insight into what changes to make and how to change. For example, I have altered assignments and discussion topics with the insight I have gained. In fact, my experience has had an impact in senior students' advanced English discussion classes where I share some of the stories I have written and proposed topics related to the concerns that these stories underscore, such as the need for English, career choices, and life transitions. The responses from these senior students have been positive, for the material and activities have become more relevant and meaningful, so much so that some students have become so keen as to increase their efforts at discussing, commenting, presenting, and writing.

Reading student journals also helps. I have continued 
asked students to keep journals, sometimes focused on student life and other times on news or public issues. When reviewing these journals, I pay more attention and learn more about individual students and the class as a whole. My interpretation of students' work has been effected by my enlightened knowledge of the individuals' life situations and responses to my teaching. For instance, I have sometimes learned of personal problems or feelings creating obstacles to a student's progress. I have even assessed a student as not suitable as an English major and recommended that a student change programs. When the students choose public issues or news stories to write about in their journals, I can see common concerns and raise them for further discussion in class or choose corresponding materials on those topics for classroom activities.

Furthermore, my experience with creative writing and journal writing has stimulated me to try to find ways to bring out student's creativity. I have encouraged students to use creative expression in their journal writing or presentation formats. As one example, I have sometimes turned a journal writing project into a scrapbook project wherein pictures, color and symbolism can enhance the written texts. As another example, I have asked students to imagine themselves as other people when writing and performing dialogues, which I think develops their understanding and empathy. We have thus worked on news panel reports and discussions, and news and talk show interviews. Too, I have students talk about their own experiences, such as dreams and childhood episodes. Through these kinds of means, my own learning develops, as I hope that of the students does. Actually, I have witnessed students coming terms with their own problems, making decisions and developing awareness about themselves and their society.

The usefulness of reflective journal writing, especially when reflecting leads to imagining the life and situation of students or research participants based on a factual foundation cannot be overstated. It can be applied far beyond foreign or second language learning and education research. There are multiple benefits for educators and social science researchers, as well as students.

\section{REFERENCES}

[1] Dyment, J. E., \& O, and O'Connell, T. S. (2003). Journal writing in experiential education: Possibilities, problems, and recommendations. Columbus, $\mathrm{OH}$ : ERIC Clearinghouse on Rural Education and Small Schools. (ERIC Document EDO-RC-03-5)F,

http://www.ericdigests.org/2005-2/journal.html, p. 2

[2] Fritson, K. K., Forrest, K. D., \& Bohl, M. L. (2011). Using reflective journaling in the college course. In R. L. Miller, E. Amsel, B. Kowalski, B. Beins, K. Keith, \& B. Peden (Eds.), Promoting student engagement, Volume 1: Programs, techniques and opportunities. Syracuse, NY: Society for the Teaching of Psychology. P. 157. Retrieved from http://cpltl.iupui.edu/media/fe1ae8ab-97b7-457e-8a47-9cf8a b581ef9/ILozKQ/cPLTLContent/2013/PLTL\%20Literature \%20PDFs/Murray_2011.pdf

[3] Humble and Sharp (2012) The Qualitative Report 2012 Volume 17, Article 96, 1-19 http://www.nova.edu/ssss/QR/QR17/humble.pdf

[4] Fritson, K. K., Forrest, K. D., \& Bohl, M. L. (2011). Using reflective journaling in the college course. In R. L. Miller, E. Amsel, B. Kowalski, B. Beins, K. Keith, \& B. Peden (Eds.), Promoting student engagement, Volume 1: Programs, techniques and opportunities. Syracuse, NY: Society for the Teaching of Psychology. P. 157. Retrieved from http://cpltl.iupui.edu/media/fe1ae8ab-97b7-457e-8a47-9cf8a b581 ef9/ILozKQ/cPLTLContent/2013/PLTL\%20Literature \%20PDFs/Murray_2011.pdf

[5] D. Byler and S. D. Iverson (2012) "Literature, Writing and Anthropology" in The Cultural Anthropology Journal (online),

p.1,2.www.culanth.org/curated-collections/5-literature-writin g-anthropology

[6] K. Narayan (2007) "Tools to Shape Texts: What Creative Non-fiction Can Offer Ethnography" in Anthropology and Humanism, Vol. 32, Issue 2 P. 130, University of California Press.

Huminist.uic.edu/docs/default-document-library/narayantool s-essay.pdf?sfvrsn=2\&sfvrsn $=2$ 